\title{
An Observance of Household Food Remains Comportment
}

\section{IJCRR}

Section: Healthcare

Sci. Journal Impact

Factor: 6.1 (2018)

ICV: 90.90 (2018)

(c) (7) (8)

Copyright@IJCRR

\section{Vinod Waiker ${ }^{1}$, Ranjit Ambad ${ }^{2}$, Abhishek Joshi ${ }^{3}$, Vijay Khandal' ${ }^{1}$}

\begin{abstract}
'Datta Meghe lnstitute of Management Studies, Nagpur, India; ${ }^{A}$ Associate Professor Department of Biochemistry Datta Meghe Medical College, Shalinitai Meghe Hospital and Research Centre, Nagpur, lndia; ${ }^{3}$ Associate Professor Dept. of Community Medicine Jawaharlal Nehru Medical College, Datta Meghe Institute of Medical Sciences, Sawangi (Meghe), Wardha, India.
\end{abstract}

\section{ABSTRACT}

Introduction: Food waste is a universal problem and attempts to curb is a big challenge worldwide as hunger rate is again rising since 2015[FAO,2017] after many years of restraint. ${ }^{1}$ As per the United Nation's Sustainable Development Goal Target 12.3.1 and 12.3.2 the food loss and waste respectively must be halved of the per capita global food targeted by 2030 . The paper aims to analyse the malpractices persist in society related to food management that leads to abundant food wastage. The percentage of food waste at the consumption stage varies from $5 \%$ in Sub-Saharan Africa to almost 58\% in North America and Oceania regions defined by FAO. Even after a continuous effort from so many years, the hunger rate is biggest challenge thought the world. Food waste broadly covers retail and consumer level food and its related losses, and thus individual plays decisive role the food waste. It is pertinent to analyse the behaviour of various factors to encourage better use of food and its products. The objective of the study is to analyse the distinctive behaviour of food waste and its upshot on society and the environment that subsequently examine the possible incentives for food waste reduction. The study also focuses on the food which turned into garbage could have been utilized by the underprivileged people and their possible distribution mechanism adopted by various agencies and NGO'S worldwide.

Aim: This study surveyed understanding the consumption, usage and wastage pattern of the household of Nagpur region. The food waste at any stage must be discouraged at its life cycle to minimize the lost effort and wastage of all applicable resources. The study reveals that the urban citizens, educated people and women's are more prone to food waste as their counterparts. There should be a rehabilitation centre created by the municipal corporation to collect, distribute and manage the food waste at the city level. This will bridge the gap of food donor and food receiver in a better way.

Material and Methods: The survey of some hundred households conducted to understand the behaviour of the food waste of the Nagpur region. As the food wasted more at the user level, thus the study behavioural factors contributing to waste practices.

Result: This suggests that Not having the proper diet plan is influencing the food waste by multiple of 0.340 , similarly overeating is also a type of food waste and influencing in multiple of 0.109. The factor which does not know how much to eat beforehand also leads to the food waste in the multiple of 0.280 . All these factors give clues that are more concern about the diet and plan someone can reduce the food waste up to a larger extent.

Conclusion: In India awareness and campaign about the food waste and its repercussion at all the platform will help to positively reduce the food waste as we did for the "Swacchta Abhiyan". Though education has negative correlation and not has only factors that we can avoid the food waste.

Key Words: Food Waste, ZERO Hunger, Waste Behaviour, Hunger Rate, Waste Management

\section{INTRODUCTION}

Food waste is crucial issues at international as well as national level. The specific target determined by the SDG 12.3 refers to the food waste at the stages of retail and consumer and food loss in stages of production, transport and storage. The global food waste indicator is the accumulation of country-wise representation of waste data and not available due to the variances in the data collection, methodology and presentation. Only $4.4 \%$ of the data are available as per FAO 12.3.1 and the rest of the data are from various other indirect sources. ${ }^{1}$ United Nation Environment helped in preparing the methodology to measure food loss and waste to identify this on the common platform worldwide.

\section{Corresponding Author:}

Dr. Vinod Waiker, Assistant Professor, Datta Meghe Institute of Management Studies, Nagpur, India. Mob: 7875804422; Email: dmimsit@yahoo.com

ISSN: 2231-2196 (Print)

Received: 24.07 .2020
ISSN: $0975-5241$ (Online)

Revised: 22.08 .2020
Accepted: 3.09 .2020
Published: 22.09 .2020 
Food loss and waste also have an impact on climate change, greenhouse gas reduction, sustainable water management, terrestrial ecosystem, forestry and biodiversity. ${ }^{2}$ As per the UN goals on Sustainable development all 17 goals for 2030 are interconnected and first two are extremely important i.e. No Poverty and Zero Hunger, whereas the second and third goal (Good Health and Well-being) is directly related to the lives of the human being. ${ }^{2}$ It emphasis more on the "Avoid throwing away food" which makes the responsibility of everyone living on the earth is to take only the amount which is required to consume. Don't store more than the required at a particular duration. Others are having a shortage of food and waiting continuously which you held up. We have limited resources to produce a finite amount of yield as per our consumption pattern.

As per the United Nations report on food and nutrition, 820 million people are not getting enough food worldwide for their healthy survival $[\mathrm{FAO}, 2019]$ and $98 \%$ of them are from developing countries. ${ }^{2}$ Insufficient nutrition causes 3.1 million children died every year and 66 million primary school children are hungry while attending the classes. As per food aid foundation, one-third of the food is wastage and only utilizing the $66.67 \%$ of the food. As per the data of the world food program, China as the most populous country is low in the Hunger Index with a score of 6.5 whereas India being a 2nd most populous country in the world, despite having self-sufficiency in food grain around $21.25 \%$ lives are not getting enough food to lead a healthy life and scored 30.3 on Global hunger Index of 2019. India had reduced this score from 38.8 in 2000 and 38.9 in 2005, still at a serious level. ${ }^{2}$ India ranked number 102 out of 117 qualifying countries on the Global Hunger Index. The trend indicator for Indian in the category of undernourished people is $15 \%$, child mortality is $4-5 \%$, the prevalence of wasting among children up to five years old is $21 \%$ and the prevalence of stunting in children under five years is approximately $38 \%$.

As the world population is increasing every hour [David Pimentel,1996], the pressure is magnified due to the rate of depletion of all non-renewable resources like Land, Water and Biological resources. ${ }^{3}$ As per the World Bank, around 1.5 to 2 billion people are malnourished under the category of moderate or severe food insure which is the highest number ever recorded. Almost $99 \%$ of the food comes from the land and only one or less than one $\%$ of the ocean and aquatic habitats. Even the agriculture growth [CPI, 2020] has increased by almost $25 \%$ since 1961 whereas the population has increased by almost $35 \% .{ }^{4}$ The gap is huge and bridging the gap is posing more challenges for all of us. After the prolonged decline of the hunger since 2015 taken the reverse direction and unfortunately it is in increasing now. ${ }^{1}$ As per the indicator defined by FAO's i.e. Prevalence of undernourishment measures how many people lack enough dietary energy to live the normal active and healthy life. The Numbers have reached to 821.6 million people or $10.8 \%$ are undernourished which is the approximate previous level of 2010. The other indicator Prevalence of moderate and severe food security based on food insecurity experience scale, about the $9.2 \%$ or more than 700 million people are having the severe level of food insecurity whereas $17.2 \%$ or 1.3 billion people are having a moderate level of food insecurity that becomes approximately 2 billion people affected

To understand the amount of food waste disposed of is not able to measure correctly, but to estimate with various measurement methodologies. Average household waste approximately $2.40 \mathrm{~kg} / \mathrm{week}$, which is comprised of around $35 \%$ of the total waste collected for a particular metropolitan city. ${ }^{5}$ Indirect method estimate quantities of food by its categories and possible waste due to economic activities and statistical measurement of total production and consumptions and far away from the real picture whereas the direct measurement gives the data just before the conversion of waste or become waste and therefore costly affair. The food waste needs to vary with household, restaurant, transportation, supply chain, packaging and with another parameter. Approximately 13\% of food waste occurs during transportation and distribution. The food waste can also vary with the seasons like winter, summer and rainy seasons. The summer and rainy seasons are more prone to deteriorate the food. The food wastage may also depend upon the size of the household or the number of people living together and their eating habits. The household size and regional differences correlated with food waste over time. ${ }^{6}$ The study also reveals that income groups also correlated with the food waste generation like high-income group families generate more waste than low-income group families. The other demographic factors like age group, education, gender, occupation and family background may also play a critical role in contributing to food waste.

India is the country where usually people do not think much about food loss and waste except very few. Barilla Centre for Food and Nutrition Foundation releases food sustainability index consider the weighted average of three category scores, namely Food loss and waste, Sustainable agriculture and Nutritional Challenges. ${ }^{7}$ Food, sustainability is about various tool and techniques encourage to educate, maintain the culture, equity and respect to all for the planet we lived on. The high score on food sustainability score means a better understanding of sustainable food and nutrition. India waste as much food as some of the other country can consume [BCFN Foundation: Food and Nutrition Sustainability Index, 2019] and about $40 \%$ of the food is wasted after production in different phases from field to feed. ${ }^{7}$ According to the agriculture ministry worth Rs.50, 000 Crores food produced is wasted per year. In another context, we see that the country's $45 \%$ of the land is degraded due to some or other reason and not available for agricultural productivity. Due to non-forests and excessive groundwater extraction, the land 
is unable to cultivate. The hunger statistics of various states of the country are very poor with the highest hunger index is from Madhya Pradesh falls in the extremely alarming category along with four other states, namely Punjab, Assam, Andhra Pradesh and Kerala fall in the serious category while twelve states are in the alarming category. Other states who are comparatively at a high level of the economic index have poor performance in curbing the hunger rate. Despite moderate economic conditions of the state around 200 million people, i.e. $15.38 \%$ of the total population are not food secure. $40 \%$ of production waste could have been used to feed $15.38 \%$ of the people in various states in a country. Around 836 million people ${ }^{23}$ survive on less than Rs. 20 a day that maybe the primary reason for the number of people (7000 Indians) die every day and 25 lakhs every year. Thus hunger is the number one cause of death in the world.

The component food loss and waste are a weighted average of the indicator in the policies to respond to food loss. India is $33^{\text {rd }}$ in the overall score of a sustainability index recorded in 67 countries with 66.40 scores, whereas France is coming first with the highest score of 76.10. In food loss and waste category India is $7^{\text {th }}$ country 81.80 and France is having the highest score with 85.80 . The separate score in the list of factors, namely food loss is 92.20 , the policy response to food loss is 100.0 and causes of distribution loss is 25.00. The second component of sustainable agriculture is a weighted average of the indicator in the water, land, emission and land-use category. In Sustainable Agriculture category, Austria is the country with the highest score of 79.90 and India is $47^{\text {th }}$ with 65.50 scores. The individual score in Environmental impact of agriculture on the water is 0.00 , the sustainability of water withdrawal is 98.40 , water scarcity is 26.70 , and sustainability of fisheries is 84.40 and 100.00 for water management and trade impact. The score for the environmental impact of agriculture on land, land users and the environmental impact of agriculture in the atmosphere is below 33 and are a very serious cause of concern as far as India is concerned. The other parameter agriculture subsidies, diversification of the agricultural system, agro-economic indicator, productivity, financial access and protection for land users are scored moderately from 33 to 67 . Other indicators land use, the impact of the land of animal feed and biofuel, land ownership, animal welfare policies, environment, biodiversity, climate change mitigations and opportunities for investing in sustainable agriculture has fairly scored more than 67. The issues related to Sustainable agriculture are having low scores in trade impact (11.10), the sustainability of fisheries (5.80), agricultural subsidies (0.0) and land productivity (22.80). India's performance is very poor in food waste and loss and food waste at the end user level is below the expected level, i.e. 31.90. This says that the end-user is wasting much of the food in the overall supply chain from farm to feed. This needs more focus on the end-user to educate for more efficient management of food and diet along with the impact of food wastage on people, society and environment. The average literacy rate of India is $69.1 \%$. The literacy rate of male and female in rural and urban India is $72.3,56.8$ and $83.7,74.8$ respectively. This shows that there is much to be done on rural India as far as education about the food waste and loss is concerned, but data shows the vice versa is also true because more food is wasted by the urban population.

Third component Nutritional challenges are a weighted average of indicator of the health and nutritional category. The case is worse for India in the Nutritional Challenge category and ranked 61th with 52.50 scores, whereas the highest score is 76.50 for Japan. Prevalence of malnourishment, Micronutrient deficiency and Number of people per fast food restaurant scores very poorly in 0.00 to 33.00 . Life of quality Enabling factors, Healthy life expectancy, Physical Activity and Diet composition are moderately scored in between 33-67. Prevalence of over-nourished, impact on health, Economic determinant of dietary patterns and Policy response to dietary patterns fairly score of more than 67 .

The other issues related to sustainable trade the Union Government has strengthened the regulatory framework like environment governing land issues, reform market regulations, allow the private sector, watershed management schemes, along with climate change adoption and mitigations. The sustainability of fisheries doesn't have a very positive approach due to overfishing and damaging aquatic life to a larger extent. India has a long way to follow standard and sustainable practice for fisheries. In India, agriculture subsidies are given in many forms, though the government is trying to reduce the subsidies in one way or another for efficient fertilizer supplier and sustainable farming methods. To improve the sustainable agriculture productivity up to fair level, some of the parameters need to be focused on priority like yield increase, water use efficiency, diversity of food grains, farm-based approaches, organic agriculture. Budget 2018-19 has taken many initiatives by the union government to reduce the amount of chemical fertilizer, water and improving the productivity at the farm level. The only sustainable and continuous effort will lead to double the income of farmer by 2022. The other factor number of people per fast food restaurant is scored low and consumption of unhealthy energy and protein sources is much higher in urban India and contributing to the emerging problem of obesity. Many such foods are adulterated with chemicals, colours, preservatives that exceeds permissible limits sometimes.

\section{MATERIAL AND METHODS}

The survey of some hundred households conducted to understand the behaviour of the food waste of the Nagpur region. As the food wasted more at the user level, thus the study 
behavioural factors contributing to waste practices. There is the individual and societal perspective to study the behaviour of food waste. ${ }^{8}$ The habit also plays a significant role in such behaviour. The habits also not modified due to lack of awareness about the facts of hunger around us. The survey, conducted in the city of Nagpur on the behavioural pattern of the food habits is household only. The scope of data collection is limited to the questionnaire filled from the user/consumer. The study did not consider the data from the food provider like restaurant, food joints and hotels. Though the food provider can calculate the total amount of food waste as per their daily wastage and based on consumption and dispatch, the habits or the pattern of food waste can only be understood at the individual level. The social places like marriage ceremonies, birthday party, rituals, lawn and Bhandara sort of place are also contributing much of the waste and not able to measure until there is any systematic way of disposing of the food waste. The study has included all representation proportionately of the society who are dominantly participating in the consumption of food and its waste. The survey is targeting to answer food consumption pattern and how it leads to waste which are difficult to measure in the quantitative term. The survey has been conducted both offline and online in case of not being accessible to the individual due to time and place constraints. Face to face interview is not considered due to the effect of the influence of the collector of the data. Stratified random sampling is used to outline various categories for the target respondent. Food provider is introduced as one more category in business occupation to reflect their effect on food waste. The analysis involves the demographic of the respondent and their respective pattern of food consumption and waste.

The sample distribution is representing the true population by considering the gender, age group, education, marital status, occupation, income and living place like urban or rural. The stratified random sampling is used to select the respondent from each category for proportionate representation in the dataset. The questionnaire is prepared based on the literature review of various articles published on food loss and the factors considered for the questionnaire are socio-demographic, household, psychological and health consciousness. The demographic diversity includes age group, education, gender, marital status, occupation, income and living place. Five points Likert Scale is used for the recording of responses (1- Never, 2- less than 2 times in a week, 3-3-6 times in a week, 4-7-8 times in a week and 5- More than 10 times in a week or always). As per the FAO, the definition of food loss involves any reason prevented to consume the food is considered as food loss and therefore the collection of responses to the behaviour that leads to waste food. The factors for food consumption like food taste, overcooked/undercooked and thrown away. ${ }^{9}$ Food purchase behaviour includes variable like to prepare a food list, food storage, use best before date food disposal to pet/animals donate the food, and leftover.10-12 The other variables are educated family member, thinking yourself about the food waste, health concern like diet plan, how much to eat, overeat etc.

\section{RESULTS AND DISCUSSION}

As per the literature survey, the study conducted for selected samples $85 \%$ of them are filled form and only considered for analysis. The Cronbach's alpha is 74.3 indicates the adequate level of internal consistency of our scale. The model summary suggests the variable food waste can be explained with the $74.4 \%$ of variations by the independent variables mentioned as below table 1 .

\section{Table 1 shows: Model Summary of variables}

\begin{tabular}{ccccc} 
Model & R & R Square & $\begin{array}{c}\text { Adjusted } \\
\text { R Square }\end{array}$ & $\begin{array}{c}\text { Std. The error of } \\
\text { the Estimate }\end{array}$ \\
1 & $0.863^{\mathrm{a}}$ & 0.744 & 0.692 & 0.45389 \\
\hline
\end{tabular}

a. Predictors: (Constant), Educate Family for Waste, Rotter Before Cook, List To Buy Food, Know-How much teat Beforehand, Over Eat, Donate Food, Feed Animal Leftover, Go Restaurant, Diet Plan, Use Best Before Date, Over Under Cooked, Eat Fast Food, Thinking of Waste, Proper Taste

This substantiates the previous study by food waste are depends largely on the variable like food taste, overcooked or undercooked, proper taste, diet plan, thinking of waste, etc. The other variable like not use the list for buying the grocery, improper storage also leads to food waste. Food disposal, donate food, call animals or pet to consume also one or another way to food waste. As per the coefficient table below, it is clear that some of the variations are not equally significant and therefore stepwise regression is done to predict the significant variables and its effect on the food waste. The other variables are having less significant result in this study that can be updated with more in-depth study or the number of samples increases showed in below table no 2 .

\begin{tabular}{|c|c|c|c|c|}
\hline Model & $\mathbf{R}$ & R Square & $\begin{array}{l}\text { Adjusted R } \\
\text { Square }\end{array}$ & $\begin{array}{l}\text { Std. The error of } \\
\text { the Estimate }\end{array}$ \\
\hline 1 & $.561 a$ & .315 & .307 & .68060 \\
\hline 2 & $.688 b$ & .473 & .460 & .60085 \\
\hline 3 & $.736 c$ & .541 & .524 & .56419 \\
\hline 4 & $.778 d$ & .605 & .585 & .52648 \\
\hline 5 & $.813 \mathrm{e}$ & .662 & .640 & .49067 \\
\hline 6 & $.828 \mathrm{f}$ & .685 & .660 & .47633 \\
\hline 7 & $.841 \mathrm{~g}$ & .708 & .681 & .46202 \\
\hline
\end{tabular}

a. Predictors: (Constant), Proper Taste, b. Predictors: (Constant), Proper Taste, Over Under Cooked, c. Predictors: (Constant), Proper Taste, Over Under Cooked, Diet Plan, d. Predic- 
tors: (Constant), Proper Taste, Over Under Cooked, Diet Plan, Know-How much tea Beforehand, e. Predictors: (Constant), Proper Taste, Over Under Cooked, Diet Plan, Know-How much eat Beforehand, List To Buy Food, f. Predictors: (Constant), Proper Taste, Over Under Cooked, Diet Plan, Know-How much eat Beforehand, List To Buy Food, Donate Food, g. Predictors: (Constant), Proper Taste, Over Under Cooked, Diet Plan, Knowhow much eat Beforehand, List To Buy Food, Donate Food, Feed Animal Leftover

Predictors are the major factors contributing to food waste. The health-related factors are judged separately by only considering three factors in the model to understand the regression of Diet Plan, Overeat and Know how much to eat beforehand on food waste and found that these variables explain $45.6 \%$ of the variations of the food waste and all the variable are significant shows in below table no 3 .

Table 3: Shows Model Summary

\begin{tabular}{ccccc} 
Model & $\mathbf{R}$ & $\begin{array}{c}\mathbf{R} \\
\text { Square }\end{array}$ & $\begin{array}{c}\text { Adjusted R } \\
\text { Square }\end{array}$ & $\begin{array}{c}\text { Std. An error of } \\
\text { the Estimate }\end{array}$ \\
\hline 1 & $.676^{\mathrm{a}}$ & .456 & .436 & .60662 \\
\hline
\end{tabular}

a. Predictors: (Constant), Know-How much eat Beforehand, Overeat, Diet Plan

\begin{tabular}{|c|c|c|c|c|c|}
\hline \multirow[t]{2}{*}{ Model } & \multicolumn{2}{|c|}{$\begin{array}{l}\text { Unstandardized } \\
\text { Coefficients }\end{array}$} & \multirow{2}{*}{$\begin{array}{c}\text { Standard- } \\
\text { ized Coef- } \\
\text { ficients } \\
\text { Beta }\end{array}$} & \multirow[t]{2}{*}{$\mathrm{t}$} & \multirow[t]{2}{*}{ Sig. } \\
\hline & B & Std. Error & & & \\
\hline (Constant) & .120 & .256 & & .467 & .641 \\
\hline OverEat & .109 & .048 & .197 & 2.274 & .026 \\
\hline DietPlan & .340 & .058 & .509 & 5.871 & .000 \\
\hline $\begin{array}{l}\text { KnowHow- } \\
\text { mucteatBe- } \\
\text { forehand }\end{array}$ & .280 & .059 & .392 & 4.744 & .000 \\
\hline
\end{tabular}

a. Dependent Variable: Food waste

This suggests that not having the proper diet plan is influencing the food waste by multiple of 0.340 , similarly, overeating is also a type of food waste and influencing in multiple of 0.109 . The factor which does not know how much to eat beforehand also leads to the food waste in the multiple of 0.280 . All these factors give clues that are more concern about the diet and plan someone can reduce the food waste up to a larger extent shows in table no 4.

\section{DISCUSSION}

All the factors as discussed above are continuing the major causes of food waste irrespective of the caste, country, region or society. The remedies are more or less common for all but the implementation differs by caste, country, region and society by its culture and individual's consciousness. This need to think in a different perspective above the self, with references to society, country, the world to the saviour of our resources and reduce the wastage. As per feedingindia.org India is the 2nd largest producer of food and 195 million people are malnourished, one-fourth of the world undernourished people are the people who live in India i.e. The three times the population of France. In India, food wastage is considered to be a part of the normal process. There is an absence of awareness among the household about the amount of food waste they are doing per day/per month or in a year is wastage of environmental resources. The people have a notion about the prepared food should always be there more than 2-3 people anytime at home and if not consumed, it leads to merely wastage. This wastage later manages by donating it to the maiden, beggar, undernourished people or pet animals. If missed then convert into waste and emitting greenhouse gases to the environment. Some of the self-help groups along with corporate, organizing the campaign against the food waste and they collect the excess food from the venue like restaurant, hotels, lawns and individual house. The vans picking up the food are checking the quality of food and keep it in customized safe and refrigerator container. This food can then be distributed to the needy people, school children and roadside people. This is the unstructured way of collecting and distributing food waste at the local level. This model should be plugged with the city civic body or Nagar Palika or Nagar Parishd. The rehabilitation centre can be created for the people who are needy, without work, without shelter and clothes. The specialized vehicle should be deployed to collect excess food and redistribute it in such rehabilitation centres. The awareness about the program should reach to the last man to contribute as per their convenience. Such Centres are important places for food donation and consumption at particular times of the day. The people who are searching for a job for their bread and butter should channelize through the centre to get easy access to labour as affordable rates. This can organize the food, waste collection and distribution along with hunger. Municipal Corporation should add one more types of minor tax for waste management i.e. 10 or 20 Rs. and get almost $1.5-2$ crore per annum if consider the population of the city is nearly 25lakhs which helps them to manage rehabilitation centre, specialized vehicle and resources required to manage along with the donation.

Food wastage in any form must be stopped and this can only be done when the individual is thinking that food as divine substance and essential for the living being. This may be the last priority for the people who have easy access to the food and never thought about saving the food for the people in need. As per Indian Vedas and Upanishad, we should also think about the type of food and its quality for better fuel- 
ling the divine vehicle i.e. our body. We spiritualize our eating from what to eat, how much to eat, when (times) to eat, how to eat (posture), to purify one's existence, receive the strength of body, mind and soul, happiness and satisfaction. ${ }^{13}$ We should always eat balanced food in a pleasant atmosphere at fixed times and never take meals in between. We should also share food with others, always give it to the other people first and then take ourselves. Do not overeat food. Put the food on the plate as much as you can eat and save any leftover for the next meal. Don't waste food in any form, don't buy too much, you buy them as much food which can be prepared and consume without rotten so that this prevents it from wastage. Think from a broader perspective, every time about the food waste and its effect on the environment.

\section{CONCLUSION}

In this study, we discussed only the controllable factor related to individual and psychological. All factors where a human has direct interface can be avoided by improving awareness and follow some of the rules. In India, awareness and campaign about the food waste and its repercussion at all the platform will help to positively reduce the food waste as we did for the "Swacchta Abhiyan". Though education has negative correlation and not has only factors that we can avoid food waste. The urban people, highly educated people or women tend to waste more food than their counterpart. ${ }^{14,15}$ The current study also substantiates along with the people who are concerned about a diet plan, overeat and know how much to eat are also contributing to food waste. This study also discussed the rehabilitation centres should start by $\mathrm{Mu}-$ nicipal Corporation of the city to bridge the gap of food donor and food receiver. There must be regular public events for awareness about the food habits and food wastage that helps to mitigate the food waste up to some extent.

Acknowledgement: Authors acknowledge the immense help received from the scholars whose articles are cited and included in references of this manuscript. The authors are also grateful to authors / editors / publishers of all those articles, journals and books from where the literature for this article has been reviewed and discussed.

\section{Conflict of Interest: Nil}

\section{Source of Funding: Nil}

\section{REFERENCES}

1. "The State of Food Security and Nutrition in the World 2017. 2017", www.fao.org, accessed on $20^{\text {th }}$ March 2020.

2. “ABOUT THE GLOBAL HUNGER INDEX.”, https://www. globalhungerindex.org, 17 Sept. 2019

3. Pimentel, David, et al. "Impact of population growth on food supplies and environment." Presented at AAAS Annual Meeting, 9 Feb. 1996
4. “Crop Production Index (2004-2006 = 100) | Data.", www.data. worldbank.org/ indicator/ AG.PRD. CROP. XD. Accessed 3 Mar. 2020.

5. Van der Werf, Paul, et al. "The Quantity of Food Waste in the Garbage Stream of Southern Ontario, Canada Households." PLOS ONE, 2018;13(6): e0198470, 10.1371/journal.pone.0198470. Accessed 4 Dec. 2019

6. Jiang, J.-Q., et al. Analysing the Size and Affecting Factors of Household Food Waste in China. 2018; 1-21

7. "BCFN Foundation: Food and Nutrition Sustainability Index.", www.foodsustainability.eiu.com/. Accessed 17 Sept. 2019.

8. Närvänen, Elina, et al. "Introduction: A Framework for Managing Food Waste.” Food Waste Management, by Lisanne, van Geffen et al. 2019,1-24.

9. Tucker, C.A., and T. Farrelly. "Household Food Waste: The Implications of Consumer Choice in Food from Purchase to Disposal." Local Environment, 2015;21(6): 682-706, 10.1080/13549839.2015.1015972. Accessed 7 Oct. 2019.

10. Koivupuro, Heta-Kaisa, et al. "Influence of Socio-Demographical, Behavioural and Attitudinal Factors on the Amount of Avoidable Food Waste Generated in Finnish Households." International Journal of Consumer Studies, 2012; 36( 2) :183-191, 10.1111/j.1470-6431.2011.01080.x

11. Porpino, Gustavo, et al. "Food Waste Paradox: Antecedents of Food Disposal in Low-Income Households." International Journal of Consumer Studies, 2015; vol. 39 (6): 619-629

12. Falasconi, L., Cicatiello, C., Franco, S., Segré, A., Setti, M., Vittuari, M. and Cusano, I. "Consumer approach to food waste: evidences from a large scale survey in Italy", Rivista di Economia Agraria, 2016; 71 (1): 266-277

13. "Feeding India.", HTTP://www.feedingindia.org. Accessed 3 Mar. 2020.

14. Stangherlin, Isadora do Carmo and Marcia Dutra de Barcellos. "Drivers and Barriers to Food Waste Reduction." British Food Journal, 2018; 120 (10): 2364-2387,

15. Silvennoinen, Kirsi, et al. "Food Waste Volume and Composition in Finnish Households." British Food Journal, 2014; 116 (6): 1058-1068,

16. Das, Bibhunandini. "Sources of Technological Knowledge and Farm Output: Evidence from a Large-Scale Farmers' Survey.” Agricultural Economics Research Review, 2018; 31(2) p. 241.

17. "Food Loss \& Waste Protocol.", www.wri.org/our-work/project/ food-loss-waste-protocol. Accessed 3 Mar. 2020

18. Freitas F, Tanise D, Anelise GR. "The Territorial Policy of Rural Development in Brazil: Questions and Reflections about the Reconnection between Production and Consumption of Food." Cuadernos de Desarrollo Rural, 2019; 16(84), 6-84.

19. "Hunger Facts | The Hunger Site for Facts: Bhookh.Com.", www.bhookh.com/hunger_facts.php. Accessed 3 Mar. 2020

20. Jörissen, Juliane, et al. "Food Waste Generation at Household Level: Results of a Survey among Employees of Two European Research Centers in Italy and Germany." Sustainability, 2015;7(3): 2695-2715, www.mdpi.com/2071-1050/7/3/2695, 10.3390/su7032695. Accessed 17 Feb. 2019

21. "Food Wastage In India, And What You Can Do About It.", www.thecsrjournal.in/food-wastage-in-India-a-serious-concern. Accessed 3 Mar. 2020.

22. Marsden, Terry, et al. "Food Supply Chain Approaches: Exploring Their Role in Rural Development." Sociologia Ruralis, vol. 40, no. 4, Oct. 2000: 424-438, www.onlinelibrary.wiley.com/ doi/10.1111/1467-9523.00158/full, 10.1111/1467-9523.00158. Accessed 5 May 2019

23. Nishat Faisal, Mohd, et al. "Information Risks Management in Supply Chains: An Assessment and Mitigation Framework." 
Journal of Enterprise Information Management, 2007; 20(6): 677-699, 10.1108/17410390710830727. Accessed 6 Mar. 2019

24. Porpino, Gustavo, et al. "Wasted Positive Intentions: The Role of Affection and Abundance on Household Food Waste." Journal of Food Products Marketing, 2016; 22 (7):733-751, 10.1080/10454446.2015.1121433. Accessed 16 Oct. 2019

25. Quested, T.E., et al. "Spaghetti Soup: The Complex World of Food Waste Behaviours." Resources, Conservation and Recycling, 2013;79: 43-51, 10.1016/j.resconrec.2013.04.011. Accessed 1 Apr. 2019

26. Rawal, Vikas, et al. "Prevalence of Undernourishment in the Indian States: Explorations Based on NSS 68th Round Data." Economic and Political Weekly, 2013; 15; 35-45

27. Second, Luca, et al. "Household Food Waste Behaviour in EU27 Countries: A Multilevel Analysis.” Food Policy, 2015;56, $25-40$.
28. "The Science of Eating and Good Health." Www.Harekrishna. Com, www.harekrishna.com/col/books/VEG/hkvc2.html. Accessed 3 Mar. 2020

29. "Welcome to the United Nations, Sustainable Development Goals.", www.un.org/ sustainable development /sustainabledevelopment-goals, accessed on $20^{\text {th }}$ March 2020

30. William J. Hussar and Tabitha M. Bailey. Projections of Education Statistics to 2019. 2011

31. Zhong, Ray, et al. "Food Supply Chain Management: Systems, Implementations, and Future Research." Industrial Management and Data Systems, 2017; 117( 9): 2085-2114, 10.1108/imds-092016-0391. Accessed 28 Apr. 2019 